\title{
Research on Technology Development and Challenges of Chinese Smart Grid
}

\author{
Xinyu Yang \\ Jinzhou Power Supply Branch \\ State Grid Liaoning Electric Power Supply Co. Ltd \\ Jinzhou, China \\ e-mail: yangxyjz@163.com
}

\author{
Peng Gao \\ Jinzhou Power Supply Branch \\ State Grid Liaoning Electric Power Supply Co. Ltd \\ Jinzhou, China \\ e-mail: gaopjz@163.com
}

\begin{abstract}
With the continuous development of society and improvement of people's living standards, people requirements for power system increasing. The smart grid is the inevitable trend of power grid development, at present China's smart grid research and construction, the prospect is optimistic. Compared with the existing power grid, smart grid reflects the significant characteristics of power flow, information flow and business flow of highly integrated .This paper analyzes the characteristics and key technologies of smart grid components, and then analyzes the architecture of the smart grid, and finally puts forward the potential problems of smart grid in china. The smart grid construction relates to the communication, control and online monitoring and other techniques; need to establish the management system and perfect market mechanism. Electric power enterprises increase the development of the smart grid which is great significance for improving the safety and reliability of the power grid; promote the electric power resources to play a greater role in national economic construction.
\end{abstract}

Keywords- renewable; restrict; quality; stability; impact (key words)

\section{INTRODUCTION}

Grid, as a modern economic development basic guarantee of important, constantly improve its energy optimization, energy supply reliability, is to meet modern production and living of local increasing demand means necessary requirements. As the market of Construction Company of our country power, smart grid also begins to enter people's field of vision, to create the new development environment in order to improve the efficiency of power supply and green environmental protection [1].

Intelligent smart grid is the grid (intellectual power), also known as "power 2", which is based on high-speed bidirectional communication network integration, advanced control method, through the sensing and measuring technology, advanced equipment, advanced technology and advanced decision support systems the realization of power grid, reliable, safe, economic, efficient, environmental friendly and safe use of the target, its main features include self-healing, incentive and users, to resist the attacks in twenty-first Century, to provide to meet user demand of power quality, to allow a variety of different forms of generation power market access, start and asset optimization and efficient operation. The smart grid is based on high-speed bidirectional communication network integration, advanced control method, through the sensing and measuring technology, advanced equipment, advanced technology and the application of advanced decision support system technology, realize the network of reliable, safety, economy, high efficiency goals, its main features include self-healing, incentive and users, to resist the attacks in twenty-first Century, to provide to meet user demand of power quality, to allow a variety of different forms of generation power market access, start and asset optimization and efficient operation. The main objective is to achieve the power grid operation, reliable, safe, economic, efficient, environmental friendly and safe use, grid can achieve these goals, and we can call it the smart grid.

Compared with the existing power grid, smart grid reflects the significant characteristics of power flow, information flow and business flow of highly integrated, advanced and advantage is mainly manifested in the: has a strong power grid system and technical support system, can resist all kinds of external interference and attacks, able to adapt to the connection of large-scale clean energy and renewable energy, strong power grid can consolidate and enhance. Information technology, sensor technology, automatic control technology and the network infrastructure of organic integration, can obtain the panorama information grid, the timely discovery; foresee the possible fault [2]. When a fault occurs, the power grid can quickly isolate the fault, the realization of self recovery, so as to avoid blackouts. Widely used soft sex / DC transmission, plant network coordination, intelligent scheduling, power storage, distribution automation technology, the power grid operation control more flexible and economic, and access and can adapt to a large amount of distributed generation, micro grid and electric vehicle charging and discharging facilities. The integrated use of communication, information and modern management technology, will greatly enhance the power equipment use efficiency, reduce the power loss, the power grid operation more economic and efficient. To realize the real-time and non real-time information sharing and utilization of highly integrated, comprehensive, complete, display and fine grid operation state diagram for the operation and management, and it can provide aided decision support the corresponding implementation plan, control and emergency plan. Establish two-way interactive service mode, the user can understand the real time capability of power supply, power quality, price status and power failure information, reasonable arrangements for electrical 
use; with electricity power enterprise users can access the information, to provide more value-added services to its[3].

\section{THE DEFINITION AND TECHNICAL FEATURE OF THE SMART GRID}

According to the definition of the national power grid in China on the smart grid, smart grid refers to the extra high voltage for the coordinated development of power grid backbone, at all levels of grid based, the use of information, communication and control of modern technology, realize the automation, information and interaction of the network technology. Intelligent smart grid, technical characteristics mainly show in the following aspects:

\section{A. Self healing}

The use of information and control system of intelligent power grid, can realize the real-time monitoring of the entire power grid, the problem is found when the fast judgment and make the protection action, such as the malfunction of the circuit or electrical component isolation, timely recovery of power supply, ensure that no large area blackout phenomenon, in addition, the real-time monitoring system can also the use of state prediction based on data on the grid, such as the large power grid according to the division level risk, prevention and control of different for different grade means.

\section{B. Interactive}

Compared with the traditional network, depending on the communication and control system of intelligent power grid, can realize bidirectional interaction, which for improving the user experience with power, has the very good effect, to establish two-way communication system between power enterprises by user, the enterprise can use electricity to users, cost, safety electricity, tariff collection were understood, the user can also according to these information make electricity plan reasonable, effective communication to achieve both supply and demand, improve the utilization rate of power resource[4].

\section{Compatibility}

Smart grid can realize the access to a variety of power generation mode, has good compatibility, in the development of distributed generation and renewable energy power generation and other power generation form, the traditional power grid is difficult to achieve these power compatible and access can be achieved, but the smart grid, smart grid can also be centralized power generation, distributed generation, renewable energy power and dye cell generation, this technology has its is of great significance for the development and utilization of renewable energy, photovoltaic enterprises of China's power grid, which greatly promoted the development of photovoltaic power generation industry, smart grid compatibility helps to improve the power structure, the green environmental protection and high efficiency utilization $\%$ of promote the development of electric power consistent with the concept of harmonious development.

\section{Optimization}

Power dispatching system of intelligent smart grid technology, according to the analysis of power grid operation data, according to the power grid, electricity distribution time distribution, power grid load transmission on power scheduling, realize the optimal operation efficiency at large to minimize the cost of the operation of power grid, smart grid can realize the power grid the loss of effective control, to identify whether energy loss under natural condition and man-made destruction of the energy loss, with modern buildings intelligent electrical system connection, will power consumption of the whole power grid to a minimum, to realize the optimization of multi link power assets planning, construction, operation, maintenance.

\section{E. Market-oriented and diversified}

Smart grid can effectively adjust the relationship between supply and demand, through to the power system planning, operation and improve the reliability of power supply, promote market-oriented operation of the electric power enterprise, to achieve fair competition in electricity market, the smart grid to transmission and distribution networks in physics as the main body, with a double to $\%$ information control system integrated $\%$ efficient as platform, implementation on power grid monitoring, control, scheduling, market operation and maintenance treatment and other business, multiple realization of integration grid service.

\section{THE COMPOSITION OF THE KEY TECHNOLOGIES OF SMART GRID}

\section{A. Intelligent communication technology}

Intelligent communication technology is one of the Butler technologies of smart grid; smart grid technology is the foundation to realize the other. Two-way, high-speed and real-time information and communication technology, can realize the real-time monitoring of power grid operation state, to provide for the study and analysis of data on the grid constantly amended and adjusted to achieve efficient use of power, improve the power supply quality and reliability; communication technology to realize the two-way communication between the power supply enterprises and power the user, to realize the equilibrium of supply and demand; information and communication technology to monitor and control the power loss and the fault, is a smart grid implementation of self-healing foundation[5].

\section{B. Intelligent sensing and control technology}

Intelligent sensing and control technology is the foundation to realize the intelligent network remote monitoring and control, mainly in the intelligent electric meter. Online monitoring equipment and wide area measurement system, smart meters can be achieved for monitoring user real-time price, electricity, but also can realize automatic meter reading, which has important significance for the construction of electrical and intelligent residential. Online monitoring system of power equipment, including the monitoring of the two part of electric and non electric quantity, electric quantity monitoring mainly includes the current, voltage, power and power factor[6]; non electric quantity monitoring mainly includes the electrical equipment temperature, pressure, gas flow and monitoring. Network online monitoring is 
carried out based on the high sensitivity of the sensor on the main voltage monitoring, circuit breaker monitoring and line capacity monitoring, wide area measurement system, refers to the basis of global positioning system and communication system, the running state of the power grid to realize dynamic measurement, and combining with the data transmission communication system to the control center to carry on the analysis, make the prevention and control of. Strong smart grid architecture as shown in Fig. 1

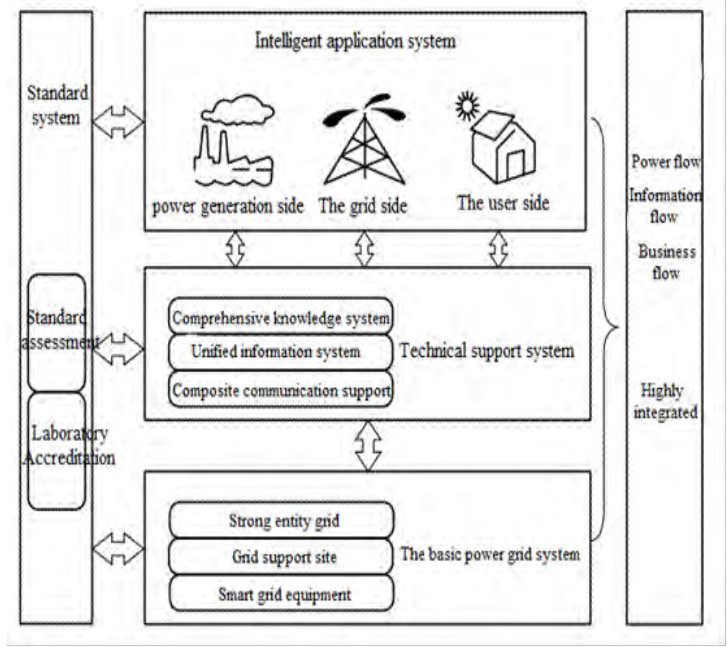

Figure 1. Strong smart grid architecture

\section{Intelligent decision system}

Decision of modern power grid on power grid dispatching personnel have strict requirements, intelligent power grid will be the traditional complex power data conversion for easy identification of animation technology, virtual reality technology, the dynamic coloring technology, help system control personnel can timely analysis and decision for the problem, caused loss of power failure. Intelligent decision system for the implementation of the modern computer technology, the visualization of humanized operation interface, accuracy of saving decision time and improve the decision-making[7].

Intelligent engineering, intelligent system is to create a variety of forms. Is not only fit in with the needs of modern economic, military and technological development, the practical application is intelligence research science and science of complexity. One of the important characteristics of intelligent system of case is the manmachine integration, integrated system based on people oriented. The practice proved that, "hall for workshop of met synthetic engineering" is an effective tool to realize scientific and democratic decision making, which can be used to support the macro economic decision-making, provide information and decision system of population, also can be in the military command, policies of major projects such as the role of scientific decision, so will the state and society and large enterprises decision-making procedures and gradually into the information society, has become the major demand of intelligent system.

\section{Access technology of distributed energy}

Access technology of distributed energy, is one of the key technologies of smart grid, which can help to realize the integration of smart grid network operation of wind power generation, photovoltaic power generation, dyes and small hydropower generation mode, not only saving transmission network construction cost, but also for the use of renewable energy extraction rate, peak load response to the power grid, improve the safety and reliability of the power grid, which has important significance[8]. The smart grid in middle and low voltage is transmission and distribution online access to distributed power, the traditional single-phase flow phenomenon to completely change the distribution of two-way and multi energy access to achieve.

\section{NEW PROBLEMS OF POWER NETWORK IN CHINA}

How to satisfy the customer to the power supply reliability, power quality and other electric power service all day of smart grid quality power supply wind farm) and large-scale distributed power supply (solar energy, wind energy, gas turbine, electric vehicle and distributed energy storage) access; various energy grid how to disposal of all kinds of renewable energy, intermittent power supply and much non-linear load access?

Wind power, solar power and other needs in grid connected to realize the effective use of its scale. Wind power, solar and other clean energy generation has the characteristics of intermittent, volatility, uncontrollable and difficult to predict, only through the grid to achieve different distribution between different types of power supply of clean energy, the adjustment, in order to realize the effective use of its scale.

At the present stage of the new energy is in a dominant position, but as the fire Hydropower of the swap, there must be a conventional energy to cooperate with each other. Wind power plant is matched with $100 \mathrm{MW}$ and 100 MW thermal power plants, in order to maximize the benefits. When there is wind to wind power output power, wind power output fluctuation, power can be matched to the output, so it can be equivalent to a stable, adjustable power, but also can reduce the power generation coal consumption, maximize the benefits of wind power generation[9]. At the same time, can the system in volatility and volatility between the power supply load configuration storage, can achieve when power supply is greater than demand of users, by the energy storage device is charged, to store excess power up; when the power supply is insufficient, the electricity consumption of large, cause frequency downward trend, then the energy storage device for the release of stored energy. To maintain stability, smart grid emphasizes the user participating in the grid control (Interactive), when the electricity peak valley changes according to the users own conditions to participate in peak shaving, can significantly improve the load peak valley difference, reduce the standby power capacity. For example, the evening is the lowest electricity, electric vehicles are to be charged at a low point, can make the whole load curve smoother. Our country has some cities began to implement the price ladder; in low power electricity will pay lower electricity. If the full is open, interactive more attractive to users participate in the grid control. Not only for power users have economic benefits of the whole power grid safe and stable and efficient operation, the comprehensive utilization rate of equipment is beneficial [10].

At present, the orderly EV charging and discharging is the domestic and international research focus, the V2G 
application is to stabilize the power grid peak valley load fluctuation, achieve an effective means of efficient and reasonable utilization of electric energy. On the other hand, the electric vehicle charging, the rectifier circuit harmonic currents injected to the power grid, power quality problems caused by the fast charging; may cause power distribution equipment capacity is insufficient, or the problem of excessive voltage drop.

Modern users for the power quality become more and more sensitive. Nonlinear, impassive load, intermittent distributed energy access, wide application of sensitive load makes the power quality problems are becoming worse. But the modern users of power quality problems become more and more sensitive to power quality requirements of higher. Like robots, automated production lines, precision instrument and equipment, numerical control machine tool and computer information system, especially some continuity of production process, such as food, chemical and semiconductor processing, once the production process is interrupted, may cause great loss of such users must adopt effective means to provide high quality power. According to the research results, familiar with the domestic users to steady-state power quality problems, but also more attention, but on the transient power quality problems, understanding and monitoring is far from enough, often a accident led to power outages, because there is no relevant monitoring means, it is difficult to determine the responsibility of the elephant, so that the supply and use of electricity to the two party electricity has the very great dispute reason quality caused by. As we all know, the voltage and current are interconvertible, harmonic current flowing through the line impedance will cause harmonic voltage drop, resulting in harmonic voltage, affect other users to the grid, at this time if the resistive load will produce harmonic current, so the responsibility is very difficult to distinguish, dispute is very big, it is urgent to solve the problem.

\section{CONCLUSION}

Grid constantly improve its energy optimization as a modern economic development basic guarantee of important, energy supply reliability, is to meet modern production and living of local increasing demand means necessary requirements. As the market of Construction Company of our country power, smart grid also begins to enter people's field of vision, to create the new development environment in order to improve the efficiency of power supply and green environmental protection. The smart grid construction relates to the communication, control and online monitoring and other techniques; need to establish the management system and perfect market mechanism. Electric power enterprises increase the development of the smart grid which is great significance for improving the safety and reliability of the power grid; promote the electric power resources to play a greater role in national economic construction.

\section{REFERENCES}

[1] C.Xue,"Overview of smart grid and its key technology," Res.Con.Env.Pro, vol.4,pp.1-4.May 2012

[2] H.B.Shi, " Development and application of smart grid technology", Sci.Tech.Inf, vol. 9, pp. 23-30,July,2012

[3] D.S. He, and Y.Q.Liu, "Grid wind power system studies , " High .Vol.Tech, vol.21, pp. 42-46,May 2008.

[4] W.Liu, " Analysis of the key technologies involved in Smart Grid " Technology and business, vol.17, pp. 18-23,June 2012

[5] Q.L.Wang, and M.Q.Zhu " The present situation and development of smart grid, " Elec.Equ, vol.19 pp. 16-19,October,2011

[6] Q.Zhang,andJ.X.Wang," Research overview of demand response in electricity market, " Aut.Ele.Pow.Sys, vol.3, pp.78-82,June 2008

[7] P.YangL.L.Sun, and N.Wu, "Grid wind power system voltage stability of the status," Comm.Ene.Tech, vol.7, pp.16-20,May 2012

[8] J.Xiao, and M.F.Zhong, " Power grid planning and design and application of comprehensive evaluation decision system," Grid technology, vol.2, pp.116-120,May 2005

[9] B.Zhang and J.Zeng, " Battery energy storage systems to improve grid power quality and stability of grid power, " Grid. Tech, vol.34, pp.21-26,May 2013

[10] J.H.Yu and H.Zhou, " Smart grid, " Pow.Grid.Clea.Ene, vol.25, pp.13-18,July 2009 